\title{
Sex, bowers and brains
}

\section{Joah Madden}

Department of Animal and Plant Sciences, University of Sheffield, Sheffield S10 2TN, UK

Inter- and intraspecific variations in the sizes of specific avian brain regions correspond to the complexity of the behaviour that they govern. However, no study has demonstrated a relationship between gross brain size and behavioural complexity, a hypothesis that has been proposed to explain the unusually large human brain. I show, using X-rays of museum specimens, that species of bowerbirds that build bowers have relatively larger brains than both related and ecologically similar but unrelated species that do not build bowers. Bower design varies across species from simple cleared courts to ornate, hut-like structures large enough to contain a small child. Furthermore, species building more complex bowers have relatively larger brains, both within each of the two different bower-building clades and across the family as a whole, controlling for phylogeny. Such gross differences in brain size are surprising and may reflect the range of cognitive processes necessary for successful bower building. The relationships are strongest for males, the bower-building sex, although there is a similar trend in females. Because the size and complexity of bower design is targeted by female choice, the observation that relative brain size is related to bower complexity suggests that sexual selection may drive gross brain enlargement.

Keywords: bowerbirds; brain size; behavioural complexity; sexual selection

\section{INTRODUCTION}

Bowers, built by males of the family Ptilonorhynchidae, are extravagant traits that incur costs due to natural selection and benefits via inter-sexual selection (Borgia 1997). Within bowerbird species, females preferentially mate with males who construct larger, better quality and more highly decorated bowers (Borgia 1985; Borgia \& Mueller 1992; Lenz 1994; Uy \& Borgia 2000). Furthermore, female choice can drive substantial changes in intraspecific bower design, potentially leading to speciation (Uy \& Borgia 2000). Bower complexity, in terms of size and design, the range of objects used as decorations and the layout of decorations in discrete, colour-defined groupings, varies widely across the Ptilonorhynchidae (Marshall 1954; Gilliard 1969). Maypole bowers, built by Prionodura and Amblyornis, consist of a central sapling onto which sticks and decorations are woven; the base of the sapling is often also surrounded with decorations. Court-clearing species, including Scenopoeetes and Archboldia, decorate their chosen display site but do not build a stick structure, yet they have been shown to be members of the maypole-building clade of bowerbirds (Kusmierski et al. 1997). Avenue bowers, built by Chlamydera, Sericulus and Ptilonorhynchus, are typified by the presence of two or more parallel walls of grass or sticks at the centre of a display court on which a variety of decorations is laid. Catbirds of the genus Ailuroedus do not build bowers.

The construction of high-quality bowers appears to require experience, learning and practice. Immature satin bowerbirds, Ptilonorhynchus violaceus, were found to bring inappropriately coloured objects and thick sticks to practice bower sites where third-, fourth- and fifth-year males appeared to play a role in the education of the younger

$\dagger$ Present address: Department of Zoology, Downing Street, Cambridge CB2 3EJ, UK (JRM54@cam.ac.uk). birds (Vellenga 1986). Maxwell (1999) confirmed that young immature satin bowerbirds spend time with older immature birds learning aspects of bower design and display. A spotted bowerbird, Chlamydera maculata, living sympatrically with satin bowerbirds outside its normal range, built a structure similar to the local satin bowerbirds' bowers and decorated it with blue objects rather than the more usual red, green and white objects (Neville 1988). Spotted bowerbirds from a population in central Queensland, Australia, built bowers similar to the sympatric great bowerbird, C.nuchalis (Frith et al. 1995). In addition to a learnt aspect of the behaviour, building a bower may also require a well-developed spatial memory, used to remember the location of supplies of decorations or neighbouring bowers, and an ability to innovate by using novel decorations or producing abnormally elaborate bower designs (Frith et al. 1994).

Learning, spatial memory and innovation have been shown to correspond to the sizes of the relevant brain regions in several other species of birds. Populations of the marsh wren, Cistothorus palustris, differ in the numbers of songs that they learn. When two such populations were compared, it was found that the volumes of two specific areas of the brain involved in song were 30-40\% larger in the population learning around 150 songs than in the population learning only about 50 songs (Canady et al. 1984). A positive correlation was found between hippocampal volume and the estimated amount of food caching (a behaviour involving spatial memory) exhibited by seven corvid species (Healy \& Krebs 1992). In an exhaustive study of feeding innovations in birds, Lefebvre et al. (1997) demonstrated a positive relationship between two measures of forebrain size and absolute and relative levels of innovation frequency. If, as seems likely, bower building is a cognitively complex task involving elaboration of a variety of brain regions then total brain volume may vary with the complexity of the bower that the bearer builds. 


\section{METHODS}

\section{(a) Calculating relative brain size}

Collecting fresh specimens for brain analysis was not feasible. Several species are listed under a range of threat categories (Collar et al. 1994). This lack of tissue precluded the measurement of individual brain components, although fine-scale differences are likely to prove important. However, good numbers of skins are held at the Rothschild Collection, Tring, UK. These skins often contain complete skulls, allowing examination by $\mathrm{X}$ ray photography. The skulls of 37 avenue builders and 33 maypole builders, along with those of ten catbirds and eight unrelated, medium-sized frugivores of Australo-Papuan forest or open woodland, were sufficiently complete to be measured (see Appendix A). These included ten species of bowerbirds and four non-bowerbird species.

The X-ray source was aligned to ensure a constant angle for photography. Two orthogonal images were taken of each skull: lateral and dorso-ventral. A scale was obtained by using a metal bar of known length placed along the centre of the skull in each image. Three measures were taken, blind to the species' identity. Length described the greatest dimension of the brain cavity along an axis passing from the bill to the back of the skull. Height described the greatest distance perpendicular to the length of the brain cavity, from skull roof to skull base. Width described the greatest distance from one side of the brain cavity to the other, perpendicular to the axis along which length was measured.

An index of brain-cavity volume, intuitively linked to maximal brain volume, was calculated by approximating the brain cavity to an ellipsoid using the formula $(\pi 6) \times$ length $\times$ height $\times$ width. Avian brain mass increases with body mass (Martin 1981). Reliable body masses were not available for several species, so instead I used skeletal information. The cube of the tarsus length provided a measure of body size (Freeman \& Jackson 1990). Mean tarsus lengths and brain-cavity volumes were calculated for each species and log transformed to achieve approximate normality (Kolmogorov-Smirnov tests, all $p>0.2$ ). Taking residuals from a regression of transformed mean tarsus lengths against transformed mean brain-cavity volumes yielded measures of relative brain size, controlling for body size. For the comparison between bowerbirds and non-bowerbirds, the regression was restricted to males and included all four non-bowerbird species. For all other analyses, I used residuals derived from regressions that included only the bowerbird species, but considered mean values for males and females separately. All sets of residuals were normally distributed (Kolmogorov-Smirnov tests, all $p>0.2$ ).

\section{(b) A bozer-complexity index}

Five species of avenue builders and four species of maypole builders/court clearers offered a range of bower complexities (figure 1). A bower-complexity index, considering both bower structure (number and size of walls or maypoles) and bower ornamentation (number, diversity and orderly arrangement of decorations), was constructed based on independent descriptions (Marshall 1954; Gilliard 1969; Diamond 1982; Borgia 1997; Kusmierski et al. 1997). Catbirds, which do not build bowers, scored one. Species that clear courts or build simple bowers with a narrow range of decorations scored two or three. Species that build ornate structures decorated with a wide range of objects arranged in discrete groupings scored four or five. Comparing two highly differing types of structures (avenues and maypoles) was problematical. Therefore, an index was constructed for each clade allowing intra-clade analyses. In order to consider phylogenetic effects across the whole family, the two indexes were combined, retaining the intra-clade scores. This produced an anomaly. The simple avenue of the regent bowerbird, Sericulus chrysocephalus, was given the same score as the cleared and decorated court of the toothbilled bowerbird, Scenopoeetes dentirostris. I repeated the cross-family analysis with S. chrysocephalus assigned scores of both two and three, and present here only the most conservative results. Bower-building species were compared with the closely related catbird Ailuroedus melanotis, which does not build bowers.

\section{RESULTS}

\section{(a) Does the bowerbird family exhibit a propensity tozvards large brains?}

I compared the mean relative brain sizes of a selection of male, medium-sized, woodland/forest frugivores representing four different passerine families from the Australo-Papuan region (specifically, Philemon novaeguineae, Sphecotheres viridis, Dicrurus bracteatus and Ptiloris magnificus) with those of male catbirds (ancestral, non-bowerbuilding bowerbirds) and bower builders (figure 2). Nonbowerbird species did not differ from catbirds in relative mean brain size (one-sample $t$-test, $t=0.19$, d.f. $=3$, $p=0.86$ ), suggesting that the family Ptilonorhynchidae does not have a predisposition for abnormally large brains. However, both catbirds and non-bowerbirds had significantly smaller brains for their body size than bower-building species (catbird versus nine bower builders: one-sample $t$-test, $t=8.48$, d.f. $=8, p<0.01$; nine bower builders versus four non-bowerbirds: MannWhitney $U$ test, $W=16.0, p=0.04$ ).

\section{(b) Do species that build more complex bowers possess correspondingly larger brains?}

I examined this question in two ways, searching for consistency in results between methods. Initially, I looked at patterns within the two separate clades: maypole builders and avenue builders. Male avenue builders, constructing more complex bowers, had significantly larger brains for their body size than those constructing simpler bowers $\left(r^{2}=0.83, \quad n=6 \quad\right.$ species, $\left.p<0.01\right)$ (figure $3 a$ ). This relationship was repeated in females, although the level of significance decreased $\left(r^{2}=0.48\right.$, $n=6$ species, $p=0.08$ ). Maypole builders mirrored these results. The relative brain size of males was significantly correlated with bower complexity $\left(r^{2}=0.81, n=5\right.$ species, $p<0.05$ ) (figure $3 b$ ). The relationship in females was not significant $\left(r^{2}=0.47, n=5\right.$ species, $\left.p=0.12\right)$. This last result may be confounded by the fact that only one female specimen was available for each of Archboldia papuensis and S. dentirostris.

A problem with this method is that species cannot be considered to be truly independent (Harvey \& Pagel 1991), yet the numbers in each clade (five and six) were low, making corrections for phylogenetic relatedness impractical. Therefore, I controlled for the effects of relatedness by using comparative analysis of independent contrasts (Purvis \& Rambert 1994), considering the family as a whole whilst retaining the same bowercomplexity scores, basing my analyses on a molecular 


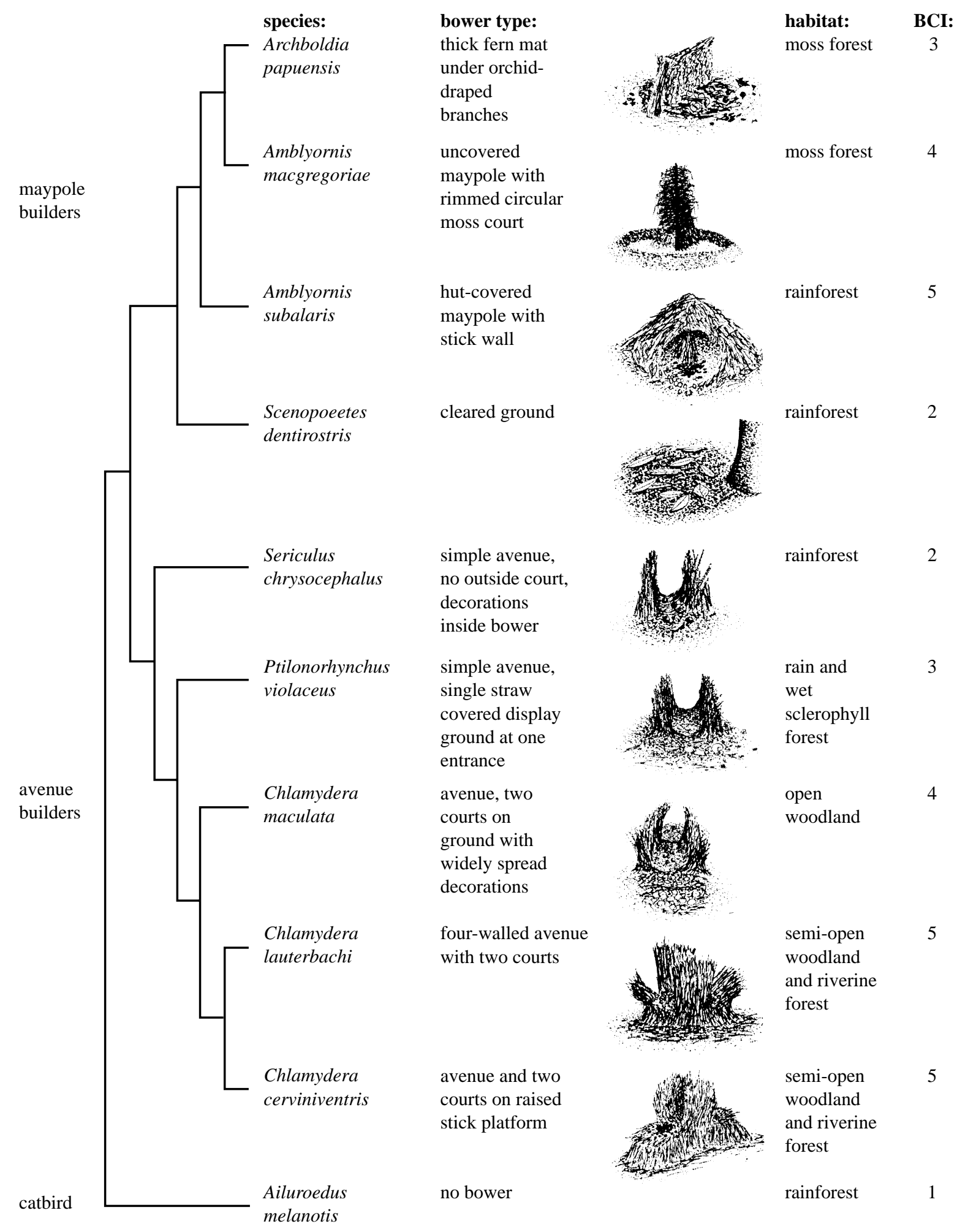

Figure 1. Relationships between the ten species of bowerbird considered in this study, based on a phylogeny constructed from mitochondrial cytochrome $b$ sequences by Kusmierski et al. (1997). Bower and habitat descriptions are taken from Kusmierski et al. (1997). BCI: bower complexity index.

phylogeny (Kusmierski et al. 1997). For males, I found a strong relationship between contrasts in relative brain size and contrasts in bower complexity $\left(p<0.01, r^{2}=0.61\right.$, $n=10$ contrasts) (figure $4 a$ ). For females, the relationship was apparent but less strong $\left(p=0.06, r^{2}=0.31, n=10\right.$ contrasts) (figure $4 b$ ).

To put these results in context, the size-corrected average brain size of males of the complex bower builder 


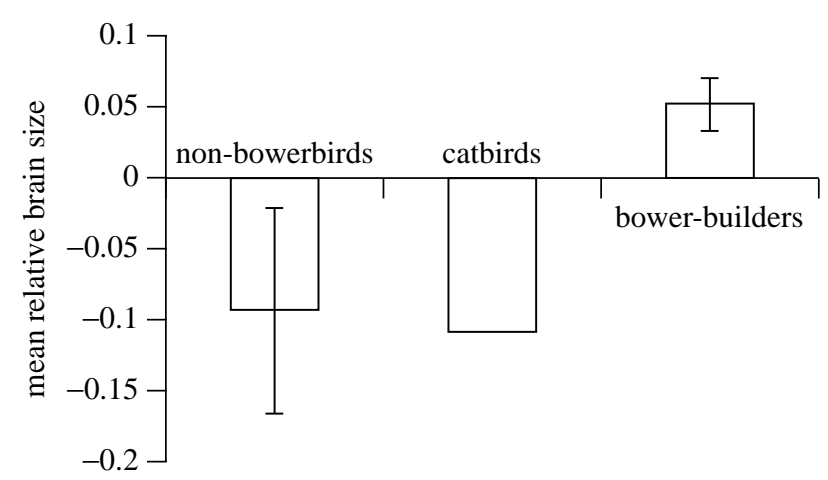

Figure 2. Mean relative brain sizes of bower builders, catbirds and non-bowerbirds. Error bars indicate \pm 1 s.e.m. (nonbowerbirds: $n=4$; catbirds: $n=1$; bower-builders: $n=9)$.

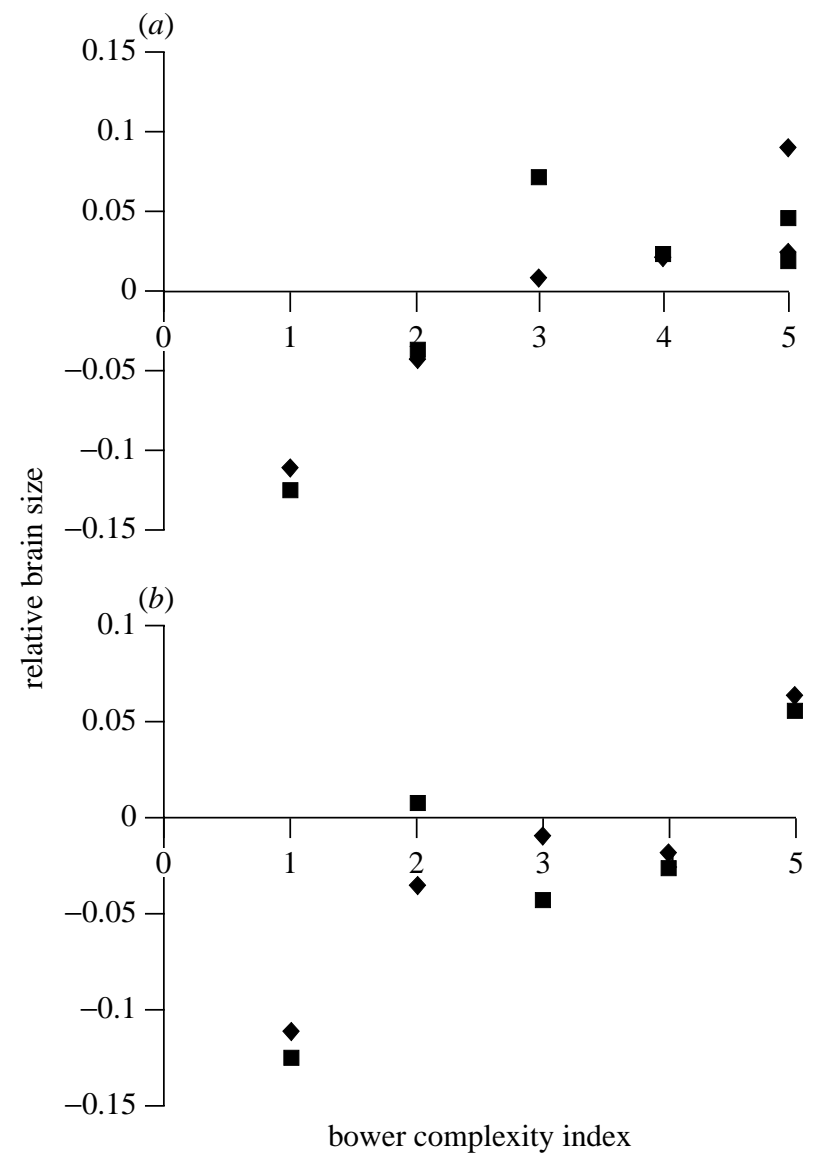

Figure 3. Plots of mean standardized residuals measuring relative brain size against bower complexity for $(a)$ avenue builders and the catbird and $(b)$ maypole builders and the catbird (males: solid diamonds; females: solid squares).

C. lauterbachi was $80.6 \%$ larger than that of the male catbird A. melanotis.

\section{DISCUSSION}

Birds building bowers have relatively larger brains than both related and unrelated species that do not build bowers. Within the bowerbird family, species that build more complex bowers possess correspondingly relatively larger brains. This is seen separately in both avenue
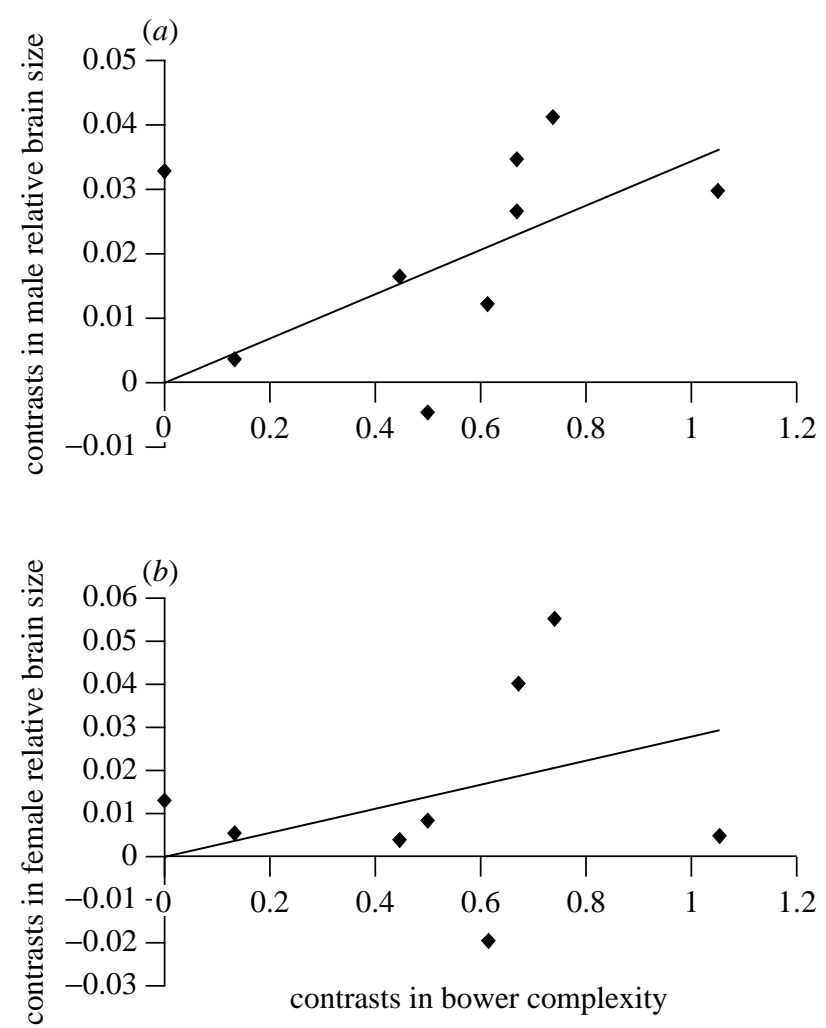

Figure 4. Regressions between contrasts for $(a)$ male and (b) female relative brain size and bower complexity with the lines forced through the origin.

builders and maypole builders, as well as across the family as a whole, and appears to be independent of potentially confounding phylogenetic effects. Moreover, all bowerbirds inhabit woodland or forest, are frugivorous and develop altricially, and the bower builders are all polygamous (the catbird is assumed to be monogamous) (Marshall 1954; Donaghey 1981; Borgia \& Mueller 1992; Lenz 1994). These similarities reduce, but of course do not entirely eliminate, the possibility that variation in brain size is driven by differences in the species' ecology, developmental history or mating strategy (Bennett \& Harvey 1985; Healy \& Krebs 1992). That catbirds do not differ from ecologically similar birds in relative brain size indicates that the bowerbird family does not have an inherent propensity for large brains. I suggest that the differences in brain size between bower builders and catbirds, and amongst bower-building bowerbirds, are not driven primarily by ecological factors but rather by the most striking behavioural differences between the species, namely the complexities of bower construction.

These results are somewhat surprising. Whilst important studies have revealed links between behaviours and specific brain regions (e.g. Kirn et al. 1989; Healy \& Krebs 1992; Székely et al. 1996), no other work has related behavioural differences to variations in gross brain size. Several other studies have demonstrated sex differences in brain-region size and related these to sexual selection targeting such traits as song (reviewed in Catchpole 1987). In this study, I have shown that although the relationship between brain size and bower complexity (a sexually selected trait) is stronger in male bowerbirds, the same trend is also seen in females. This finding can be 
explained in two ways. First, females may benefit from a corresponding increase in brain size for similar reasons to males, specifically, an increased ability to analyse and compare more innovative or complex bower structures and improved spatial memory to facilitate returning to chosen bower sites after initial assessment (Uy et al. 2000). Second, a non-exclusive alternative is that female brain size may have co-evolved alongside male brain size due to pleiotropy, yet remains selectively neutral (Lande 1980; Lindenfors \& Tullberg 1998). Fine-scale neuroanatomical studies may clarify this by revealing sex differences in specific brain regions.

This relationship between brain size and a sexually selected trait provides some indirect support for the hypothesis put forward by Miller (2000) that sexual selection may drive the evolution of the abnormally large human brain in response to female choice targeting novel, complex male behaviours. Bowerbirds provide one of the very few examples in biology of the building of ornate physical structures purely for the purposes of sexual display. I have demonstrated here a correlation between the complexity of such a display and relative brain size.

I thank R. Prys-Jones, M. Adams, D. Smith and F. Steinheimer at Tring and acknowledge the Rothschild Collection for the generous provision of the skins. X-ray facilities were supplied by V. Polland at Bow House Dental Practice. I was supported by a Natural Environment Research Council studentship and a grant from The Royal Society to A. Balmford. A. Balmford, T. Birkhead, S. Conway-Morris, E. Cunningham, J. Endler, R. Johnstone, A. Russell and two anonymous referees provided helpful comments on earlier versions of this manuscript. M. Symonds assisted with C.A.I.C.

\section{APPENDIX A}

Specimens used in this work and their Natural History Museum, Tring, UK, identification numbers are given below.

\begin{tabular}{|c|c|c|c|c|c|}
\hline species & $\operatorname{sex}$ & identification number & species & $\operatorname{sex}$ & identification number \\
\hline Ailuroedus melanotis & $\mathrm{F}$ & 1964.60 .1400 & C.lauterbachi & $\mathrm{M}$ & 1949.62 .101 \\
\hline A. melanotis & $\mathrm{F}$ & 1964.60 .1403 & C. lauterbachi & $\mathrm{M}$ & 1953.17 .228 \\
\hline A. melanotis & $\mathrm{F}$ & 1964.60 .1405 & Chlamydera maculata & $\mathrm{F}$ & 1964.60 .1419 \\
\hline A. melanotis & $\mathrm{F}$ & 1964.60 .1407 & C. maculata & $\mathrm{F}$ & 1964.60 .1421 \\
\hline A. melanotis & $\mathrm{F}$ & 1964.60 .1410 & C. maculata & $\mathrm{M}$ & 1964.60 .1420 \\
\hline A. melanotis & M & 1964.60 .1399 & C. maculata & $\mathrm{M}$ & 1964.60 .1422 \\
\hline A. melanotis & M & 1964.60 .1401 & C. maculata & M & 1964.60 .1423 \\
\hline A. melanotis & M & 1964.60 .1404 & C. maculata & $\mathrm{M}$ & 1964.60 .1424 \\
\hline A. melanotis & M & 1964.60 .1411 & C. maculata & $\mathrm{M}$ & 1964.60 .1425 \\
\hline A. melanotis & M & 1964.60 .1412 & C. maculata & $\mathrm{M}$ & 1964.17 .658 \\
\hline Amblyornis m. macgregoriae & $\mathrm{F}$ & 1904.4 .19 .29 & Dicrurus bracteatus & $\mathrm{M}$ & 1916.5.30.877 \\
\hline A.m.macgregoriae & $\mathrm{F}$ & 1911.12 .22 .71 & D.bracteatus & $\mathrm{M}$ & 1916.5.30.901 \\
\hline A.m. macgregoriae & $\mathrm{F}$ & 1913.3.6.155 & Philemon novaeguineae & $\mathrm{M}$ & 81.5 .1 .4161 \\
\hline A.m. macgregoriae & M & 1913.3.6.153 & P. novaguineua & $\mathrm{M}$ & 1925.11 .1 .689 \\
\hline A.m. macgregoriae & M & 1949.62 .88 & Ptilonorhynchus v. violaceus & $\mathrm{F}$ & 1900.6 .11 .41 \\
\hline A.m. macgregoriae & M & 1949.62 .89 & P.v.violaceus & $\mathrm{F}$ & 1939.12.9.2134 \\
\hline A.m.macgregoriae & M & 1949.62 .90 & P.v.violaceus & $\mathrm{F}$ & 1939.12 .9 .2135 \\
\hline A.m. macgregoriae & $\mathrm{M}$ & 1953.17 .224 & P.v.violaceus & $\mathrm{F}$ & 1969.41 .1054 \\
\hline A.m.macgregoriae & M & 1953.17 .225 & P.v.violaceus & $\mathrm{M}$ & 4 \\
\hline Amblyornis subularis & $\mathrm{F}$ & 1911.12 .22 .70 & P.v.violaceus & $\mathrm{M}$ & 81.11 .7 .367 \\
\hline A. subularis & $\mathrm{F}$ & 1913.3.6.146 & P.v.violaceus & $\mathrm{M}$ & 93.4 .4 .60 \\
\hline A. subularis & $\mathrm{F}$ & 1913.3.6.147 & P.v.violaceus & $\mathrm{M}$ & 1900.6 .11 .40 \\
\hline A. subularis & $\mathrm{F}$ & 1970.2 .42 & P.v.violaceus & $\mathrm{M}$ & 1969.49 .51 \\
\hline A. subularis & M & 1911.12 .22 .66 & Ptiloris magnificus & $\mathrm{M}$ & 1916.5 .30 .1328 \\
\hline A. subularis & M & 1913.3.6.152 & P. magnificus & $\mathrm{M}$ & 1916.5 .30 .1331 \\
\hline A. subularis & M & 1932.12 .21 .69 & Scenopoeetes dentirostris & $\mathrm{F}$ & 85.11 .19 .2 \\
\hline A. subularis & M & 1969.41 .807 & S.dentirostris & $\mathrm{M}$ & 85.11 .19 .1 \\
\hline A. subularis & M & 1969.41 .809 & S.dentirostris & $\mathrm{M}$ & 90.9 .19 .21 \\
\hline Archboldia papuensis & $\mathrm{F}$ & $1953.17 .222 \mathrm{~b}$ & S. dentirostris & $\mathrm{M}$ & 90.9 .19 .22 \\
\hline A.papuensis & M & 1953.17 .217 & S. dentirostris & $\mathrm{M}$ & 93.4 .4 .132 \\
\hline A.papuensis & M & 1953.17 .218 & S.dentirostris & $\mathrm{M}$ & 1964.60 .1413 \\
\hline A.papuensis & M & 1953.17 .219 & S. dentirostris & M & 1964.60 .1414 \\
\hline A.papuensis & M & 1953.17 .220 & Sericulus chrysocephalus & $\mathrm{F}$ & 72.2 .10 .21 \\
\hline A.papuensis & M & 1953.17 .221 & S.chrysocephalus & $\mathrm{F}$ & 81.11 .7 .371 \\
\hline A.papuensis & M & 1953.17 .222 & S.chrysocephalus & $\mathrm{F}$ & 1955.6.n6.26 \\
\hline A.papuensis & M & 1965.29 .32 & S.chrysocephalus & $\mathrm{M}$ & 45.3 .15 .26 \\
\hline Chlamydera cerviniventris & $\mathrm{F}$ & 1939.12 .9 .1537 & S.chrysocephalus & $\mathrm{M}$ & 72.2 .10 .20 \\
\hline C.cerviniventris & $\mathrm{F}$ & 1970.2 .23 & S.chrysocephalus & $\mathrm{M}$ & 95.4 .5 .58 \\
\hline C.cerviniventris & M & 1925.11.1.332 & S.chrysocephalus & $\mathrm{M}$ & 1900.6 .11 .43 \\
\hline C.cerviniventris & $\mathrm{M}$ & 1939.12.9.2731 & S. chrysocephalus & $\mathrm{M}$ & 1943.4.19.2 \\
\hline Chlamydera lauterbachi & $\mathrm{F}$ & 1916.5 .30 .1013 & S.chrysocephalus & $\mathrm{M}$ & 1955.6.n6.25 \\
\hline C. lauterbachi & $\mathrm{F}$ & 1953.17 .229 & S.chrysocephalus & $\mathrm{M}$ & 1969.41 .784 \\
\hline C. lauterbachi & $\mathrm{F}$ & 1953.17 .230 & Sphecotheres viridis & $\mathrm{M}$ & 60.9 .5 .77 \\
\hline C. lauterbachi & M & 1949.62 .100 & S.viridis & $\mathrm{M}$ & 1969.29 .493 \\
\hline
\end{tabular}

Proc. R. Soc. Lond. B (2001) 


\section{REFERENCES}

Bennett, P. M. \& Harvey, P. H. 1985 Relative brain size and ecology in birds. F. Zool. Lond. A 207, 151-169.

Borgia, G. 1985 Bower quality, number of decorations and mating success of male satin bowerbirds (Ptilonorhynchus violaceus): an experimental analysis. Anim. Behav. 33, 266-271.

Borgia, G. 1997 Comparative behavioural and biochemical studies of bowerbirds and the evolution of bower-building. In Biodiversity, II (ed. M. L. Reaka-Kudla, D. E. Wilson \& E. O. Wilson), pp. 263-276. Washington D.C.: Joseph Henry Press.

Borgia, G. \& Mueller, U. 1992 Bower destruction, decoration stealing and female choice in the spotted bowerbird Chlamydera maculata. Ети 92, 11-18.

Canady, R. A., Kroodsma, D. E. \& Nottebohm, F. 1984 Population differences in complexity of a learned skill are correlated with the brain space involved. Proc. Natl Acad. Sci. USA 81, 6232-6234.

Catchpole, C. K. 1987 Bird songs, sexual selection and female choice. Trends Ecol. Evol. 2, 94-97.

Collar, N. J., Crosby, M. J. \& Stattersfield, A. J. 1994 Birds to watch 2: the world list of threatened birds. Cambridge, UK: BirdLife International (BirdLife Conservation Series No. 4).

Diamond, J. M. 1982 Rediscovery of the yellow-fronted gardener bowerbird. Science 216, 431-434.

Donaghey, R. 1981 Parental strategies in the green catbird (Ailuroedus crassisrostris) and the satin bowerbird (Ptilonorhynchus violaceus). $\mathrm{PhD}$ thesis, Monash University, Melbourne, Australia.

Freeman, S. \& Jackson, W. M. 1990 Univariate metrics are not adequate to measure avian body size. Auk 107, 69-74.

Frith, C. B., Frith, D. W. \& Wieneke, J. 1994 An exceptionally elaborate bower structure of the great bowerbird Chlamydera nuchalis (Ptilonorhynchidae) Aust. Bird Watch. 15, 314-319.

Frith, G. B., Frith, D. W. \& McCullough, M. 1995 Great and spotted bowerbirds Chlamydera nuchalis and C.maculata (Ptilonorhynchidae) sympatric and interacting at each other's bowers. Aust. Bird Watch. 16, 49-57.

Gilliard, E. T. 1969 Birds of paradise and bowerbirds. London: Weidenfeld \& Nicolson.

Harvey, P. H. \& Pagel, M. D. 1991 The comparative method in evolutionary biology. Oxford University Press.

Healy, S. D. \& Krebs, J. R. 1992 Food storing and the hippocampus in corvids: amount and size are correlated. Proc. $R$. Soc. Lond. B 248, 241-245.
Kirn, J. R., Clower, R. P., Kroodsma, D. E. \& DeVoogd, T. J. 1989 Song-related brain regions in the red-winged blackbird are affected by sex and season but not repertoire size. $\mathcal{F}$. Neurobiol. 20, 139-163.

Kusmierski, R., Borgia, G., Uy, A. \& Crosier, R. H. 1997 Labile evolution of display traits in bowerbirds indicates reduced effects of phylogenetic constraint. Proc. R. Soc. Lond. B 264, 307-313.

Lande, R. 1980 Sexual dimorphism, sexual selection and adaptation in polygenic characters. Evolution 34, 292-307.

Lefebvre, L., Whittle, P., Lascaris, E. \& Finkelstein, A. 1997 Feeding innovations and forebrain size in birds. Anim. Behav. 53, 549-560.

Lenz, N. 1994 Mating behaviour and sexual competition in the regent bowerbird Sericulus chrysocephalus. Eти 94, 263-272.

Lindenfors, P. \& Tullberg, B. S. 1998 Phylogenetic analyses of primate size evolution: the consequences of sexual selection. Biol. 7. Linn. Soc. 64, 413-447.

Marshall, A. J. 1954 Bowerbirds: their display and breeding cycle. Oxford University Press.

Martin, R. D. 1981 Relative brain size and basal metabolic rate in terrestrial vertebrates. Nature 293, 57-60.

Maxwell, P. S. 1999 Learning in immature male satin bowerbirds (Ptilonorhynchus violaceus). BSc thesis, University of Queensland, Brisbane, Australia.

Miller, G. 2000 The mating mind: how sexual choice shaped the evolution of human nature. London: William Heinemann.

Neville, B. 1988 The strange case of Billy Bowerbird. Geo 10, 73-79.

Purvis, A. \& Rambert, A. 1994 Comparative analysis by independent contrasts $(C A I C)$ v. 2. Oxford, UK: Oxford University.

Székely, T., Catchpole, G. K., DeVoogd, A., Marchl, Z. \& DeVoogd, T. 1996 Evolutionary changes in the song control area of the brain (HVC) are associated with evolutionary changes in song repertoire among European warblers (Sylviidae). Proc. R. Soc. Lond. B 263, 607-610.

Uy, J. A. C. \& Borgia, G. 2000 Sexual selection drives rapid divergence in bowerbird display traits. Evolution 54, 273-278.

Uy, J. A. C., Patricelli, G. L. \& Borgia, G. 2000 Dynamic mate-searching tactic allows female satin bowerbirds Ptilonorhynchus violaceus to reduce searching. Proc. R. Soc. Lond. B 267, 251-256.

Vellenga, R. 1986 Bower-building behaviour of immature satin bowerbirds Ptilonorhynchus violaceus. Aust. Bird Watch. 11, 166-167. 